\title{
IDENTIFICAÇÃO E CULPA: QUESTÕES ÉTICAS CONTEMPORÂNEAS
}

Oswaldo França Neto

Professor do

Programa de

Pós-graduação

em Estudos

Psicanalíticos

(UFMG).

Psicanalista.
RESUMO: Freud colocou o processo de identificação na gênese do aparelho psíquico. Enquanto conceito, porém, ele é marcado por alguns paradoxos. Este artigo se propõe a formalizar tais impasses, assim como a necessária vinculação, no texto freudiano, do conceito de identificação com o fenômeno da culpa. Em seguida, serão levantadas al gumas situações contemporâneas nas quais, aos olhos da psicanálise e do sistema jurídico, essa vinculação (identificação-culpa) tem sido colocada em questão.

Palavras-chave: Identificação, culpa, ética, moral, direito.

ABSTRACT: Identification and guilt: contemporary ethical questions. Freud has presented the process of identification in the origin of the psychic apparatus. As a concept, though, it is marked by a few paradoxes. This article aims to formalize such impasses, as well as the necessary link, in a Freudian text, of the concept of identification with the guilt phenomenon. Throughout the text, a number of contemporary situations will be drawn upon, where within the areas of psychoanalysis and the judicial system, this link (identification-guilt) has come into serious question.

Keywords: Identification, guilt, ethics, morals, law.

$\mathrm{O}^{\mathrm{s}}$ percurso dos estudos de Freud foi marcado pela tentativa le solucionar uma série de impasses que, com freqüência, eram frutos dos desdobramentos das próprias elaborações de seu autor. Duas dessas dificuldades foram os conceitos de narcisismo e de identificação, conceitos estes que, posteriormente, em 1915, seriam colocados em estreita correlação. Mas a história deles começa bem antes.

Em 1900, nessa caixa de sonhos que é o aparelho psíquico, e cujo funcionamento é pautado por uma produção significativa que tende ao infinito, cada vez mais foi se tornando premente buscar um aprimoramento na descrição daquilo que serviria como referência primeira (ou última) para o deslizar 
metonímico. Dificuldade similar, porém em outro contexto, apareceu nos Três ensaios (1905), no qual, ao tematizar a sexualidade, tornou-se claro a necessidade de uma explicação para a enigmática transposição das pulsões parciais em direção a algum tipo de unificação, única situação possível para trabalharmos com uma concepção de sujeito. Nesses dois momentos ( 1900 e 1905), o que urgia era o bom delineamento da referência que conectaria, ou daria noção de conjunto, ao que se apresentava como sem sentido ou fragmentado.

Em 1909, em uma reunião da Sociedade Psicanalítica deViena, Freud utiliza pela primeira vez o termo 'narcisismo', propondo-o como fase intermediária necessária entre 0 auto-erotismo e 0 amor objetal. 0 narcisismo seria aquele ingrediente essencial que nos permitiria passar das parcialidades ao Um.

Mas, logo de início, colocou-se a dificuldade conceitual em discernir com nitidez o narcisismo daquilo que o precederia. Era necessário supor algo, "uma nova ação psíquica" (FREUD, 1914/ 1974, p.93), para que o narcisismo pudesse existir. N essa "nova ação" podemos reencontrar o tema, ou motivo, deste texto: a identificação. Em 1915, no artigo "Luto e melancolia", Freud tematiza a relação entre estes dois termos. Na melancolia, a escolha inicial do objeto teria sido feita sobre uma base narcísica, escolha que é convertida em “identificação narcísica". Alguns anos mais tarde, em 1921, no texto "Psicologia das massas e análise do eu" , a importância do fenômeno de identificação é ampliada. 0 próprio eu passa a ser entendido como se constituindo a partir de identificações. Ele seria o resultado da sedimentação dos investimentos de objetos abandonados, contendo, dessa forma, a história das escolhas objetais do sujeito. Nessa época, mais especificamente em 1923 ( 0 eu eo isso), Freud utiliza a expressão "identificação primária" para designar o que ele entendia como sendo "uma identificação direta e imediata, que se efetua mais primitivamente do que qualquer catexia de objeto" (FREUD, 1923/ 1976, p.45-6). Nessa identificação primária, que se daria logo no início da fase oral primitiva do indivíduo, "a catexia do objeto e a identificação são, sem dúvida, indistinguíveis uma da outra" (idem, p.43).

É importante salientar que, ao descrever, na identificação primária, uma nãodiferenciação entre investimento de objeto e identificação, Freud está propondo algo que, aos olhos da lógica clássica, é formalmente impossível. Ele está propondo que nós igualemos "ter" ( "investimento de objeto" ou desejar ter um objeto) com "ser" (identificar-se com o objeto). A distinção entre os dois já havia sido atestada pelo próprio Freud dois anos antes:

"É fácil enunciar numa fórmula a distinção entre a identificação com o pai e a escoIha deste como objeto. No primeiro caso, o pai é o que gostaríamos de se; no segundo, o que gostaríamos de ter, ou seja, a distinção depende de o laço se ligar ao sujeito ou ao objeto do eu." (FREUD, 1921/ 1996, p.116) 
Em 1924, no artigo "A dissolução do complexo de Édipo", Freud reconhece nessa distinção a resolução do conflito edipiano: inicialmente, o menino deseja ter a mãe; a saída do Édipo se dá quando ele se desloca desse lugar de ter (desejar a mãe), para o lugar de ser (identificar-se com o pai). Ou seja, apesar de podermos propor a transformação de um em outro, trata-se de dois processos claramente distintos. Como então imaginar uma situação primeira ("identificação primária" ), em que ter e ser sejam a mesma coisa?Ter a si mesmo como elemento, igual ando ser e ter, cria uma situação paradoxal. Quando propomos queA é $B$ $(A=B)$, estamos estabel ecendo uma igualdade. Porém, quando dizemos que $A$ contém $B(A \supset B)$, somos obrigados a aceitar que $A$ é maior do que $B$. Ao igualar essas duas sentenças - $(A=B)$ e $(A \supset B)-$ Freud está afirmando, em termos matemáticos, que um dado elemento é maior do que si mesmo:

$$
(A=B) \text { e }(A \supset B) \Rightarrow(A \supset A)
$$

Essa formulação está em consonância com as elaborações deAlain Badiou em seu livro 0 ser e o evento (1996). Trabalhando sob a perspectiva da teoria dos conjuntos, este filósofo francês propõe que aquilo que fundaria o sujeito seria um acontecimento indiscernível em relação ao contexto no qual surge. Essa indiscernibilidade seria resultante de uma característica específica - ser elemento de si mesmo - o que Ihe concederia um caráter paradoxal. Ao apresentar-se como se contendo como elemento $(A \supset A)$, este acontecimento carrearia uma diferença irredutível com relação a si mesmo, tornando-se assim uma referência que, apesar de fundar e determinar a cadeia significante, seria inapreensível por esta.

A identificação primária, ao constituir-se como marca fundadora, inscrevese, ao mesmo tempo, como um único elemento e dois elementos diferentes. Ela carreia em si o seu oposto, que é a instauração, no próprio seio, de uma diferença irredutível consigo mesma. Este é um dos primeiros impasses desse difícil conceito.

Em 1923 (0 eu e 0 isso), com a segunda formulação do aparelho psíquico, todas as instâncias que se diferenciam do (no) isso se constituem a partir do processo de identificação. Segundo Freud, o isso seria constituído por representações de objeto (representações estas catexizadas), em oposição ao mundo externo, onde estariam os objetos propriamente ditos. Na identificação, uma representação de objeto passa a ser tratada como objeto (externo). Adquire o status de objeto, apesar de continuar a ser representação.

Observamos aqui uma nova dificuldade conceitual. A identificação é, ao mesmo tempo, representação (interno) e objeto (externo). 0 eu, que é instaurado e constituído por identificações, é, ao mesmo tempo, interno (ele é uma diferenciação do isso, sendo então constituído por representações catexizadas), e 
externo (visto e tratado como um objeto propriamente dito). Ou seja, na identificação, ou no ponto de identificação, iguala-se interno e externo, o que é outra situação paradoxal. Freud fala dessa dificuldade:

“(...) o eu é, em sua própria essência, sujeito; como pode ser transformado em objeto? Bem, não há dúvida de que pode sê-lo. 0 eu pode tomar-se a si próprio como objeto, pode tratar-se como trata outros objetos, pode observar-se, criticar-se, sabese lá o que pode fazer consigo mesmo. Nisto, uma parte do eu se coloca contra a parte restante. Assim, o eu pode ser dividido; divide-se durante numerosas funções suas - pelo menos temporariamente. Depois, suas partes podem juntar-se novamente." (FREUD, 1933 [1932]/ 1976, p.76-77)

0 eu, enquanto identificação, é, ao mesmo tempo, sujeito (investe representações) e objeto (é investido pulsionalmente, inclusive por si próprio). Embora se tratando de uma diferenciação do isso e, portanto, não deixando de ter com ele algum tipo de continuidade (dentro), o eu é visto pelo isso como objeto (fora).

O mesmo ocorre com o supereu:

"Assim, temos afirmado repetidamente que o eu é formado, em grande parte, a partir de identificações que tomam o lugar de catexias abandonadas pelo isso; que a primeira dessas identificações sempre se comporta como uma instância especial no eu e dele se mantém à parte sob a forma de um supereu: (...)." (FREUD, 1923/ 1976, p. 64, grifo nosso)

Ou seja, o supereu tem a ambígua posi ção de tanto ser parte do eu quanto ter uma existência separada deste:

“(...) reconhecendo que al go tem existência separada, Ihe damos um nome que Ihe seja seu, de ora em diante descreverei essa instância existenteno eu como o 'supereu'." (FREUD, 1933 [1932]/ 1976, p.78, grifo nosso)

O supereu é, ao mesmo tempo, "dentro" (uma diferenciação do eu) e "fora" ( trata o eu como objeto).

Mas as dificuldades conceituais da identificação não se restringem a esses dois pares de opostos (dentro/ fora, ser/ ter). Há também uma outra, dessa vez de caráter temporal. Ao propor que o supereu corresponderia à primeira das identificações ( ver antes), e levando-se em consideração que o eu é constituído por identificações, somos levados a pensar que o supereu precederia o eu, ou pelo menos que sua instauração seria correlativa à gênese do eu. Freud, porém, 
em vários momentos, descreve-o textualmente como instância geneticamente secundária, uma diferenciação do eu:

"O amplo resultado geral da fase sexual dominada pelo complexo de Édipo pode, portanto, ser tomada como sendo a formação de um precipitado no au (....). Esta modificação do eu retém a sua posi ção especial; ela se confronta com os outros conteúdos do eu como um ideal do eu ou supereu." (FREUD, 1923/ 1976, p.49, grifo nosso)

Ou seja, o supereu é uma diferenciação daquilo que ele, enquanto identificação primeira, constitui ( causa = efeito). Estamos às voltas com outro paradoxo, dessa vez de caráter temporal.

Essa última ambigüidade também pode ser observada quando tematizamos a gênese do eu. Antes do eu, não haveria, a rigor, diferenciação entre isso (dentro) e mundo externo (fora), ou entre a criança e a mãe. É o eu que, ao se constituir, vai fazer essa separação. Só que ele se constitui a partir da identificação de algo de dentro com algo de fora. 0 eu é resultado da identificação entre elementos que ele próprio diferenciou ao constituir-se.

N osso aparel ho psíquico edifica-se a partir de uma situação paradoxal que, na verdade, é tríplice (dentro $=$ fora, ser $=$ ter, causa $=$ efeito) . É baseando-se nesse fato que Lacan, em um dado momento, vai afirmar que os neuróticos são desorientados por natureza, já que a referência primordial que os determina como sujeitos só se deixa formular por meio de enunciações antagônicas. Seguindo Descartes e seu cogito, a única afirmação que podemos atestar como tendo estatuto de verdade é o fato de existirmos como sujeitos durante o breve instante em que nos apreendemos como pensamento. Mas qualquer afirmação com relação ao conteúdo do que pensamos está irremediavelmente marcada pela dúvida. 0 aparelho psíquico constitui-se a partir do que chamamos de paradoxos, que, por definição, são a coexistência de afirmações que, apesar de excludentes, são igualmente verossímeis.

Em algumas situações clínicas parece que essa ambigüidade constitutiva da identificação primária estaria ausente. Isso é o que se pode verificar, por exemplo, quando Freud discorre sobre a PMD (psicose maníaco-depressiva, hoje denominada distúrbio bipolar) em 1933:

“( ...) durante um surto melancólico seu supereu se torna super severo, insulta, humilha e maltrata o pobre eu, ameaça-o com os mais duros castigos, recrimina-o por atos do passado mais remoto, que haviam sido considerados, à época, insignificantes (...). 0 supereu aplica o mais rígido padrão de moral ao eu indefeso que lhe fica à mercế; (...) Em determinadas formas da doença (mania), na verdade, passa-se al go de tipo contrário, nos intervalos; o eu encontra-se em um estado beatífico de exaltação, 
celebra um triunfo, como se o supereu tivesse perdido toda a sua força ou estivesse fundido no eu (...)." (FREUD, 1933 [1932]/ 1976, p.79-80, grifo nosso)

Freud nos leva aqui a pensar que na PMD o processo de identificação teria particularidades próprias, distintas das que ocorrem na neurose. Enquanto na neurose a identificação estaria marcada pela ambigüidade (ao mesmo tempo dentro e fora), na PMD, durante as crises, essa ambigüidade se perderia. Em uma crise de melancolia, o supereu tornar-se-ia completamente distinto do eu, tratando-o como puro objeto, enquanto que na mania, inversamente, haveria uma fusão do eu com o supereu, tornando-se ambos uma só instância. Algo similar parece ocorrer na paranóia, quando o agente inquisidor encontra-se completamente deslocado para fora.

Esse necessário caráter paradoxal da identificação - uma vez que seu esvaecimento poderia estar na gênese, por exemplo, das psicoses - serve para demonstrar a impossibilidade de se tamponar a hiância implicada na gênese do sujeito. Nós nos constituímos a partir da separação de uma unidade originária (mãe-filho), e, após esse momento, tal unidade tornar-se-á al go sempre buscado, mas necessariamente jamais al cançável. Essa impossi bilidade de reencontrar a completude é estabelecida justamente pela ambigüi dade da operação que nos constitui como sujeito. As ferramentas de que dispomos para a tarefa de retorno ao Todo - a identificação e seus avatares - têm algo de paradoxal no seu processar.

Freud externou, em 1933, nunca ter ficado satisfeito com suas elaborações sobre a identificação. M as, talvez, essas dificuldades não reflitam apenas imprecisões conceituais a serem revistas. Com os impasses formais do conceito de identificação, Freud estaria evidenciando a ambigüidade constitutiva de todo ser humano, condenado, como atestou Descartes, à impossibilidade em estabelecer de forma definitiva a verdade sobre aquilo que o determina.

\section{IDENTIFICAÇÃO E CULPA}

A identificação freudiana comporta ainda uma outra ambigüidade, esta agora conseqüência da concepção de que nela tratar-se-ia primariamente da incorporação de algo que originalmente teria tido existência externa. 0 supereu, assim, seria tributário da introjeção da lei parental. Essa concepção, que vincula a constituição do sujeito a uma instância transcendente, também poderia ser lida em certo período do ensino de Lacan, em torno dos anos 1950, quando el " parecia atrelado a um simbólico a priori, nova versão de um quadro transcendental que fixa as coordenadas de nossa existência" (GARCIA, 2002, p.308).

Por ser imposta de fora, alguma coisa que somos obrigados a aceitar sem escoIha, a identificação passa necessariamente a vincular-se a uma outra ambigüidade: 
o pai é al guém a quem amamos (nos identificamos e desejamos ser como ele) e a quem odiamos (já que interdita-nos exatamente de ser como ele, ao vedar-nos 0 acesso à mãe). Na incorporação da lei parental, impõe-se um traço externo, ao mesmo tempo referência segura (ideal do eu) e interdição (supereu). 0 pai torna-se, assim, ambiguamente amado e odiado, o que faz com que a percepção desse ódio acarrete no sujeito um sentimento de culpa paralisante. Temos na neurose obsessiva a manifestação por excelência de tal processo. Não é à toa que, em Freud, ideal do eu e supereu cheguem às vezes a se confundir. Ambas as instâncias, tributárias do mesmo processo de introjeção, são intimamente relacionadas, e a culpa é a evidência maior dessa origem comum.

Mas existiria uma forma de ao mesmo tempo resguardar a ação da identificação e escapar da culpa que a acompanha. Seria por meio da perversão. Nesta haveria uma recusa (Verleugnung) em aceitar a castração, ou seja, uma espécie de aceitação da identificação, porém recusando o que nela é interdição. 0 perverso, dessa forma, por meio de um artifício, manter-se-ia à margem da lei, através da assunção de um referente (o fetiche) que, diferentemente do neurótico, não carrearia consigo a interdição da mãe. Ao "desvencilhar-se" dos avatares da lei paterna, o perverso ver-se-ia livre da culpa. Isso não implica que ele também não pague um preço por sua existência como sujeito. Se o perverso liberta-se da interdição (e da culpa que a acompanha) , torna-se, no entanto, escravo daquilo que a encobre. Da interdição vocênão pode gozar, ele se vê agora obrigado a sujeitarse ao imperativo você deve buscar o gozo, sempre, e dessa única manéra.

A ciência, de uma forma diferente da perversão, também se propõe amoral. Enquanto na perversão há uma recusa da castração, ao mesmo tempo que mantendo a presença viva daquilo (fetiche) que garantiria a identificação, a ciência funciona como se o processo de identificação (e seu caráter paradoxal) não lhe concernisse. No campo da ciência, a lei não se coloca como questão. Ao se propor universal, e partir do princípio de que seus enunciados são irrefutáveis, a ciência rejeita (Ververfung) a necessidade de uma identificação fundadora, assim como a possibilidade da transgressão. Uma lei só é tematizável se confrontada com sua transgressão. Ao negar a possibilidade desta última, a ciência exclui de seu campo de questionamentos a lei que estaria na sua gênese. A ciência, dessa forma, coloca-se exterior ao processo de internalização (introjeção) e de seus avatares (moral e culpa).

Segundo Foucault (1975), o que permitiu que a loucura deixasse de ser um fenômeno relativo e adquirisse, paulatinamente, uma especificidade própria, foi o fato de seu confinamento institucional, a partir do século XIX, ter adquirido 0 caráter de um regime moral único. Neste novo mundo asilar, mundo da moral que castiga, a loucura pôde final mente inscrever-se na dimensão da interioridade, recebendo, então, status, estrutura e significação psicológicos. Aos olhos de 
Foucault, a psicologização da loucura só se tornou possível a partir do momento em que ela se dei xou apreender por uma perspectiva moral e pelo avatar de sua internalização - a culpa. Foi apenas a partir do momento em que a sociedade passou a tratar conscientemente o louco de forma cruel, partindo do pressuposto que ele estaria moralmente errado, que a postulação de uma lógica do psíquico (psico-logia) pôde ser formulada. Essa internalização da loucura (manifestada fenomenicamente pela culpa) teria possibilitado, com Freud, o aparecimento da psicanálise. Se algum dia a ciência vier a conseguir estabelecer de forma indubitável e irredutível o fator causal das patologias psíquicas, inserindo-as em uma universalidade biológica, estas serão definitivamente desculpabilizadas, e uma "psicologia" perderá sentido.

\section{QUESTÕES ÉTICAS CONTEMPORÂNEAS}

Agora que já estabelecemos a necessária vinculação da identificação freudiana com a culpa, podemos discutir al gumas questões levantadas por autores contemporâneos que talvez nos ajudem a problematizar, ou mesmo colocar em dúvida, a universalidade dessa vinculação.

Recentemente, em texto veiculado pela mídia impressa, ao trabalhar a adaptação feita para o cinema da obra de Patrícia Highsmith, Slavoj Zizek defende que Tom Ripley, princi pal personagem criado por essa autora e protagonista de cinco de seus romances, seria ético, porém amoral (ZIZEK, 2004).

Em 0 talentoso Ripley, por exemplo, o personagem em questão, um jovem novaiorquino sem dinheiro, fica fascinado pela vida fácil, elegante, luxuosa e socialmente aceitável levada por Dickie, filho de um magnata também americano. Ripley, então, de maneira engenhosa, mata Dickie, assume sua identidade e, fazendo-se passar por ele, organiza tudo de modo que, após a morte "oficial" da vítima, herde sua fortuna. Quando isso acontece, o falso Dickie desaparece, deixando uma carta na qual anuncia o próprio suicídio e elogiaTom, que então reaparece, engana os investigadores policiais e até ganha a gratidão dos pais do "suicida".

Segundo Zizek, Dickie teria se tornado um modelo, uma espécie de eu ideal para Ripley, alguém "capaz de saber como desejar" (ZIZEK, 2004, p.6) e com quem ele se identificaria imaginariamente. 0 traço mais perturbador de nosso personagem principal, porém, seria a ausência do mais elementar sentido moral. Não se trataria de um perverso, ou seja, ele não sente prazer em matar. Só o faz quando não existe outro meio para conseguir o que deseja, e mesmo assim pratica-o meio a contragosto, da forma mais rápida e indolor possível. Mas não há em Ripley o menor sinal de culpa. Tudo se passa como se ele fosse "uma espécie de anjo, que vive num universo anterior à lei e sua transgressão, isto é, anterior ao círculo vicioso da culpa gerado pela própria obediência à lei" (idem). Para Zizek, por estar anterior à lei, Ripley não estaria totalmente integrado à rede 
simbólica. Isso seria atestado pela sua incapacidade de viver intensamente o sexo, intensidade esta que só pode existir no universo da lei simbólica. Seria como se Ripley vivesse em um "vazio de subjetividade", um indivíduo amável e obsequioso, embora com alguma frieza, incapaz de viver com paixão o que quer que seja. Tratar-se-ia de um bom exemplo para uma certa "normalidade", proposta e definida por Lacan como sendo uma forma especial de psicose, "uma forma de não ficar traumaticamente preso à rede simbólica, de conservar a 'liberdade' da ordem simbólica" (idem). Há aqui, segundo Zizek, uma dissociação entre moralidade e ética. Apesar de ser capaz de identificar com clareza a direção de seu desejo e empenhar-se na sua realização (ética) , este personagem não estaria submetido a nenhuma lei externa introjetada (moral) , o que o deixaria livre da culpa.

Fica-nos, então, a questão se Ripley, desvinculado da culpa (sem ser perverso), e não integrado completamente à rede simbólica (talvez uma espécie de psicose), teria sido afetado pela identificação no sentido freudiano do termo. Trata-se, aos olhos de Zizek, de um sujeito capaz de desejar ( ético), porém anterior à assunção (introjeção) da lei simbólica. Será que podemos falar em um ideal do eu, ou estaria el e movido apenas pelo eu ideal? Encontrando-se em uma situação que seria anterior à introjeção simbólica ( portanto desvinculado da culpa), como entender em Ripley a categoria de identificação? Poderíamos inclusive nos perguntar sobre o real estatuto do desejo nesse personagem - é correto utilizarmos o termo "desejo", em seu sentido psicanalítico, quando da inexistência de uma inscrição que o funde enquanto campo?

Mas, por enquanto, aparentemente estamos fal ando de uma situação específica, na qual pensaríamos na ocorrência de um "defeito" na inscrição simbólica, uma espécie de exceção do que normal mente se espera. Contudo, o número de situações que têm suscitado discussões com relação ao posicionamento do sujeito frente à lei simbólica está aumentando e se tornando, por exemplo, uma importante questão para o sistema judiciário.

Há pouco tempo, acontecimento amplamente divulgado pela mídia colocou em discussão a questão da inimputabilidade. Guerreiros da tribo indígena Cintas-Largas, no estado de Rondônia, protagonizaram uma chacina de mais de 40 garimpeiros que invadiram suas terras. Os índios, assim como os menores de idade e os doentes mentais, são entendidos como grupos especiais aos ol hos do sistema jurídico. Por serem considerados como não capazes de avaliar as conseqüências de seus atos perante as normas vigentes da sociedade em questão, 0 julgamento de seus delitos tendem a receber tratamento especial. Em entrevista concedida por um dos caci ques na ocasião, ficou claro que eles em nada estavam afetados por qualquer tipo de sentimento de culpa pelo ato que cometeram. A presença de culpabilidade é em geral referência para pressuposição jurídica de 
imputabilidade. Como nos lembra Célio Garcia, a "situação ideal desde sempre considerada pela Filosofia e pela Doutrina Jurídica seria a coincidência entre responsabilidade civil e responsabilidade moral" (GARCIA, 2002, p.322) . 0 autor de um crime tende a ser considerado inimputável e, portanto, não suscetível de cumprir pena, quando não é capaz de entender que o ato cometido é ilícito, incapacidade esta atestada pela ausência de sentimento de culpa. Mas Célio ressalva que a nossa contemporaneidade, a partir do momento em "que nos dispusemos a admitir sistemas cognitivos diferenciados" (idem), tem apresentado situações que resistem a estabelecer de forma consensual a imputabilidade, o que vem a comprometer a noção de responsabilidade. Na França, por exemplo, há claramente uma tendência em considerar cada vez mais as perturbações psiquiátricas como agravantes, e não atenuantes, as prisões tornando-se sucedâneas do hospital psiquiátrico, este último oficialmente em vias de extinção. E o que dizer do nosso personagem Ripley? Devemos considerá-lo inimputável? Apesar de, por algum "defeito" de inscrição, ele não ter introjetado as leis sociais (o que 0 libertaria da responsabilidade moral), devemos desresponsabilizá-lo por seusatos?

Cyro Marcos da Silva, ao aliar sua experiência de juiz com sua atividade atual como psicanalista, fala de uma responsabilidade ética:

“Na neurose, a responsabilidade é um determinante ético: é a possibilidade que 0 neurótico tem de sair de sua posição paralisada, entre culpa e irresponsabilidade. (...) A ética da psicanálise o leva a ocupar outro lugar na divisão, ou seja, não mais dividido entre culpa e irresponsabilidade, mas entre, sim, responsabilidade e aquilo que Ihe determina. Paradoxo ético!" (SILVA, 1997 apud GARCIA, 2002, p.322)

Vemos a culpa sair de cena, a partir de uma outra postura ética. 0 fato de val orizar o desejo em detrimento da culpa não significa que a psicanálise desresponsabilize 0 sujeito. Adquirir liberdade com relação à paralisia provocada pela culpa não implica que o sujeito não se apresente como responsável por aquilo que deseja e pel os atos que faz para realizá-lo. É a partir dessa responsabilização ética, inclusive, que ele vai poder passar a existir como sujeito.

Trabal hando com menores infratores, a discussão sobre a necessária vinculação entre responsabilidade e culpa torna-se premente. De acordo com Garcia, esses jovens, com freqüência, não se mostram receptivos a aceitar o que chamamos de culpa neurótica, o que não implica que não sejam capazes de falar sobre seu ato. Apesar de no momento do acting out o sujeito estar ausente, "sua responsabilidade como sujeito por vezes só é assumida após a realização do delito" (GARCIA, 2002, p.327). 0 ato cria o sujeito, o que nos leva novamente a pensar em uma responsabilidade não necessariamente atrelada à noção de culpa. Para a psicanálise, independentemente de considerá-lo ou não inimputável aos olhos 
do sistema judiciário, desresponsabilizar o jovem infrator seria desconhecê-lo como sujeito de seu ato, seria cavar um fosso entre o delinqüente e qualquer possibilidade de intervenção terapêutica.

Recentemente, em cursos ministrados em Paris, naÉcole Normale Supérieure ( aos quais tivemos a oportunidade de freqüentar em 2000 e 2001), Alain Badiou vem propondo um transcendental ligado a uma situação local. Não se trata de instância superior, alteridade inatingível ou estrutura universal, mas de um grande Outro interno, referido à situação. U m transcendental imanente, que nos permite pensar em uma identificação desvinculada da hegemonia do simbólico (Lacan dos anos 1950), e que se apresenta localmente, na esfera do real. Por estar na situação e manifestar-se nela, diferentemente de Kant, não se trata de estrutura velada, apesar de persistir como estrutura de ordem, fixando as medidas possíveis de identidade entre dois entes. De acordo com a discussão que estamos desenvolvendo aqui, seria uma forma possível de pensarmos em uma identificação referida ao registro da imanência e, portanto, relativizada com relação à perspectiva de "introjeção". No transcendental imanente proposto por Badiou, aquilo que determinaria o sujeito presentificar-se-ia em si, como inscrição singular, não mais tributária de uma determinação externa ( e dos fenômenos de culpa que a acompanham). Esses cursos, porém, ainda não passaram para o papel. Badiou promete para breve publicação uma espécie de continuação de seu livro maior ( 0 ser e 0 evento), no qual esse tema será fio condutor. Tal vez encontremos aí uma contribuição a mais para uma discussão que, ao que parece, longe está de terminar...

Recebido em 23/ 4/ 2004. Aprovado em 29/ 12/ 2004.

\section{REFERÊNCIAS}

BADIOU, A. (1996) 0 ser e o evento, Rio de Janeiro: Jorge Zahar.

FOUCAULT, M. (1975) Doença mental epsicologia, Rio de Janeiro: Tempo Brasileiro.

FRANÇA NETO, O. (1999) "Consi derações matemáticas sobre o gozo na neurose e na psicose", in Ágora, v. VII n. 2, Rio de Janeiro, Contra Capa, jul/ dez, p.81-94.

FREUD, S. (1972-1996) Edição standard brasileira das obras psicológicas completas de Sigmund Freud, Rio de Janeiro: Imago.

(1924) “A dissolução do complexo de Édipo", v. XIX.

(1900) "A interpretação de sonhos", v. IV eV.

(1896) "Carta 52", v. I.

(1933[1932]) "Conferência XXXI", v. XXII.

(1917) "Luto e melancolia", v. XIV. 
(1923) "O ego e o id", v. XIX.

(1921) "Psicologia de grupo e a análise do ego", v. XVIII.

(1914) "Sobre o narcisismo: uma introdução", v. XIV.

(1905) "Três ensaios sobre a teoria da sexualidade", v. VII.

GARCIA, C. (2002) "Lacan e companhia”, in SAFATLE, V. (org.), Um limite tenso: Lacan entre a filosofia e a psicanálise, São Paulo: Unesp.

SILVA, C. M. da. (1997) 0 louco, dito irresponsável, no Códi go Penal, Juiz de Fora (MG): Unijui.

ZIZEK, S. (2004) "Sensibilidade para a inércia", in Caderno Mais!, Folha de S. Paulo, São Paulo, 8 de fevereiro, p.4-6.

Oswaldo França N eto

oswaldofranca@yahoo.com 